\title{
Meeting report: National symposium on infectious agents and cancer
}

\author{
Lisa Petermann $\mathrm{PhD}^{1}$, David McLean $\mathrm{MD}^{2,3}$, Gavin Stuart $\mathrm{MD}^{3}$, Morris Sherman MB BCh PhD ${ }^{4}$, Eduardo Franco PhD
}

\begin{abstract}
$\mathrm{T}$ he relationship between neoplasia and infectious agents has long been known, but has not been well understood. While knowledge of carcinogenic mechanisms, and of prevention and treatment options is increasing, it has often been generated in such a manner as to limit its dissemination among traditional disciplines and content areas. For example, knowledge about hepatitis B virus as a carcinogen and the development and uptake of vaccines to control transmission may not be fully understood by cervical cancer investigators who might use such knowledge to enhance the implementation of population-based human papillomavirus (HPV) vaccination.

Recognizing the need for increased knowledge exchange among researchers, practitioners and policy specialists interested in infectious agents and cancer, the National Infectious Agents Committee of the Canadian Partnership Against Cancer's Primary Prevention Action Group organized a symposium in Toronto, Ontario, between March 11 and 12,2010 . The purpose of the event was to explore the existing body of knowledge in basic science, clinical interventions and policy work related to HPV, hepatitis B and C viruses, and Helicobacter pylori as cancercausing agents, and to seek opportunities for cross-pollination or innovative investigations that may further enhance knowledge in these domains and stimulate the transition from research to action. The meeting brought together 54 experts from across the country, allowing for a diversity of perspectives from different fields and geographical regions. International speakers were also invited to showcase existing global best practices. The symposium covered the basic bioscience, epidemiology, clinical, public health and policy implications for each of these infectious agents as they relate to cancer. The present report summarizes the principal themes and ideas that emerged from the presentations and breakout group discussions during this symposium.
\end{abstract}

\section{BACKGROUND}

HPV is among the most common sexually transmitted infectious agents. More than 40 genotypes of HPV can infect the anogenital mucosa of women and men who become sexually active. Most infections clear spontaneously within one to two years, or become undetectable by the most sensitive molecular techniques. A small proportion of women who become persistently infected with high oncogenic risk HPV genotypes (particularly HPV-16) develop precancerous cervical lesions known as cervical intraepithelial neoplasia. If not detected and treated via screening, high-grade cervical intraepithelial neoplasia may progress to cervical cancer (1). HPV infection is considered to be a necessary, but not sufficient, cause of cervical cancer. The multifactorial model of cervical cancer etiology suggests an interplay of various cofactors. Smoking, high parity, long-term use of oral contraceptives, coinfections and immunosuppression have been found to increase risk. Other factors, such as genetic polymorphisms in the human leukocyte antigen system and in some oncogenes, as well as nutrition and viral characteristics, also seem to affect risk. The establishment of HPV infection as the primary causal agent in cervical carcinogenesis has ushered in a new era in cancer control, namely, the development of prophylactic vaccines against HPV and new molecular techniques to be used in cervical cancer screening (2). HPV infection is also an important causal agent in most anogenital cancers and some types of oropharyngeal carcinomas in men and women.

Primary liver cancer, also known as hepatocellular carcinoma (HCC), is one of the few cancers for which the cause is known. The association between chronic hepatitis $\mathrm{B}$ infection and the development of liver cancer was recognized in the 1970s, and confirmed in a classical prospective cohort study (3). The advent of vaccination against hepatitis B provided the first cancer vaccine, long before HPV vaccination (4). Hepatitis C was identified in the early 1990s and, shortly thereafter, it was also shown to cause HCC (5). HCC, particularly in the developed world, can also have a nonviral causation - nonalcoholic fatty liver disease. The prevention of infection using vaccines and other means should reduce the prevalence of HCC.

Cancer of the stomach is usually caused by a chronic infection with Helicobacter pylori - a Gram-negative microaerophilic bacterium that can flourish in a highly acidic environment such as the stomach. It can cause chronic inflammation that can lead to gastric and duodenal ulcers, and to stomach cancer. Perhaps 50\% of the world is infected with this bacterium - most commonly in low-income countries (6). H pylori produces an enzyme that neutralizes stomach acid, but with the production of irritating ammonia. Chronic inflammation can be carcinogenic for many tissues and, as with hepatitis virus and the liver, may be the mechanism for the evolution of stomach cancer. Antibiotic therapy can be curative.

\section{MEETING OUTCOMES}

The meeting achieved its primary goal of increasing awareness of the existing body of knowledge in basic science, clinical interventions and policy work related to HPV, hepatitis B and H pylori as causes of cancer. Presentations from both national and international experts highlighted the key issues in each of these areas for all three symposium themes, leading participants to note that 'the talks were excellent - a cut above the usual'. It is more challenging to measure the relative success in achieving the second purpose of the event - seeking opportunities for crosspollination or innovative investigation that may further enhance knowledge in these domains and stimulate the transition from research to action, although several participants did state that the key pearl learned at the event was 'the need for more interdisciplinary approaches'. The symposium produced a range of ideas concerning infectious agents and cancer. Participants identified the need for continued interaction to foster multidisciplinary thinking, with particular emphasis on screening, surveillance and vaccines related to infectious agents and cancer.

For a more complete report of the meeting, please refer to the following website: www.partnershipagainstcancer.ca/wp-content/uploads/NIAFINAL-REPORT-for-CPAC-website-Dec-1__v2_.pdf

\section{REFERENCES}

1. Franco EL, Duarte-Franco E, Ferenczy A. Cervical cancer: Epidemiology, prevention and the role of human papillomavirus infection. CMAJ 2001;164:1017-25.

2. Trottier H, Franco EL. The epidemiology of genital human papillomavirus infection. Vaccine 2006;24(Suppl 1):S1-15.

3. Beasley RP, Hwang LY, Lin CC, Chien CS. Hepatocellular carcinoma and hepatitis B virus. A prospective study of 22,707 men in Taiwan. Lancet 1981;2:1129-33.

4. Chang MH, Chen CJ, Lai MS, et al. Universal hepatitis B vaccination in Taiwan and the incidence of hepatocellular carcinoma in children. Taiwan Childhood Hepatoma Study Group. N Engl J Med 1997;336:1855-9.

5. Sun CA, Wu DM, Lin CC, et al. Incidence and cofactors of hepatitis $\mathrm{C}$ virus-related hepatocellular carcinoma: A prospective study of 12,008 men in Taiwan. Am J Epidemiol 2003;157:674-82.

6. Pritchard DM, Crabtree JE. Helicobacter pylori and gastric cancer. Curr Opin Gastroenterol 2006;22:620-5.

\footnotetext{
${ }^{1}$ Canadian Partnership Against Cancer, Toronto, Ontario; ${ }^{2}$ BC Cancer Agency; ${ }^{3}$ University of British Columbia, Vancouver, British Columbia;

${ }^{4}$ University Health Network and the University of Toronto, Toronto, Ontario; ${ }^{5}$ Division of Cancer Epidemiology, McGill University, Montreal, Quebec Correspondence: Dr Lisa Petermann, Primary Prevention Action Group, Canadian Partnership Against Cancer, 1 University Avenue, Suite 300,

Toronto, Ontario M5J 2P1. Telephone 403-698-8146, fax 403-355-3292, e-mail lisa.petermann@partnershipagainstcancer.ca
} 


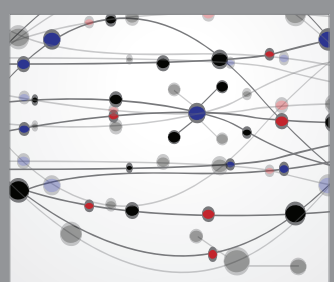

The Scientific World Journal
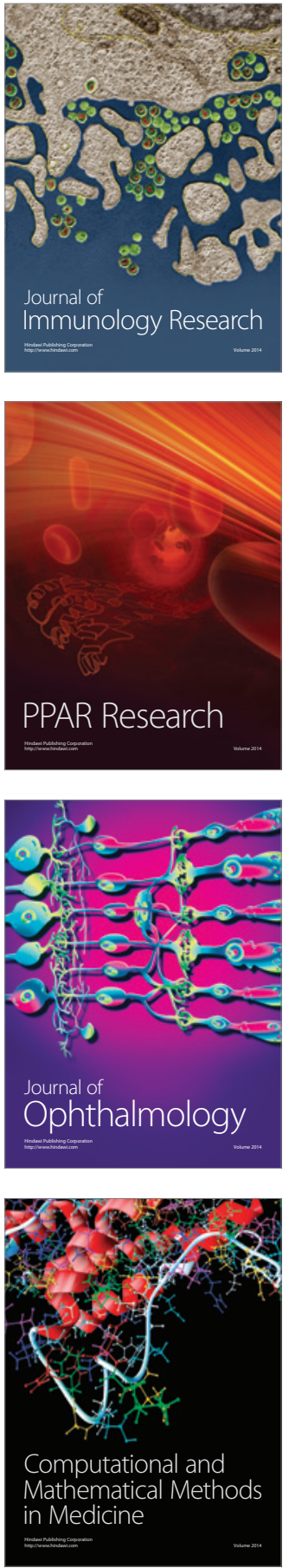

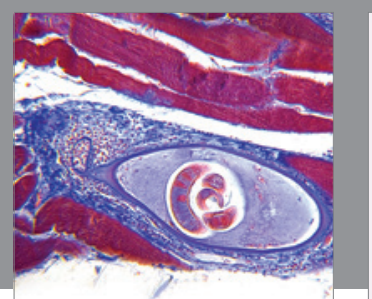

Gastroenterology Research and Practice

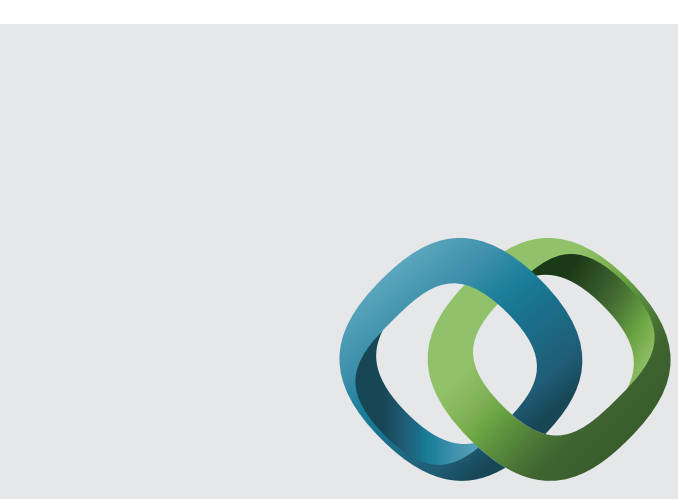

\section{Hindawi}

Submit your manuscripts at

http://www.hindawi.com
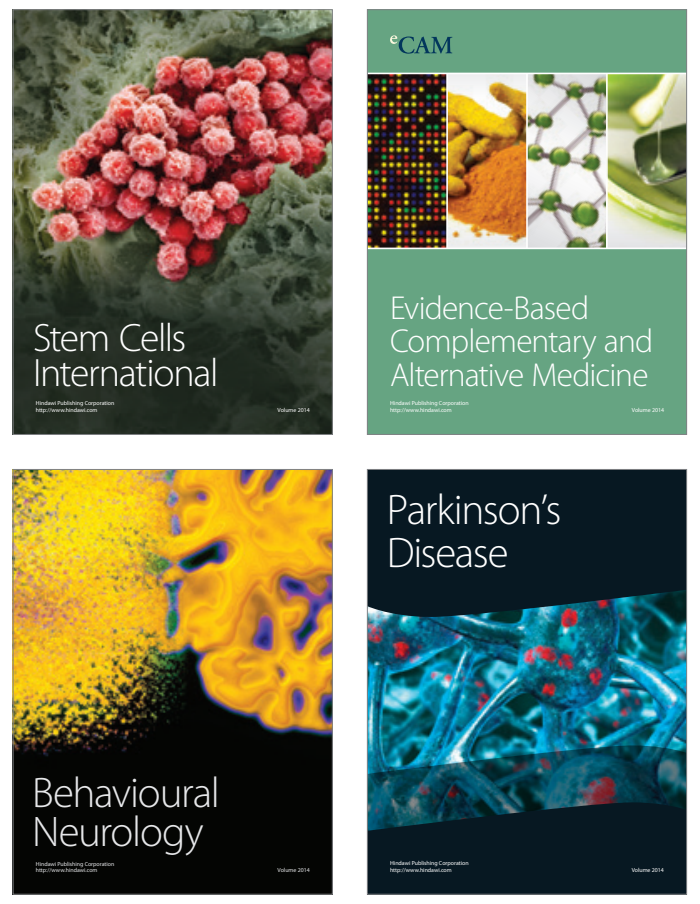
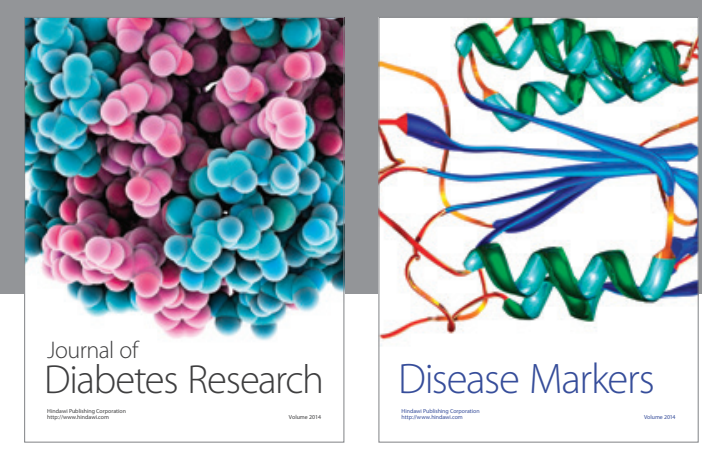

Disease Markers
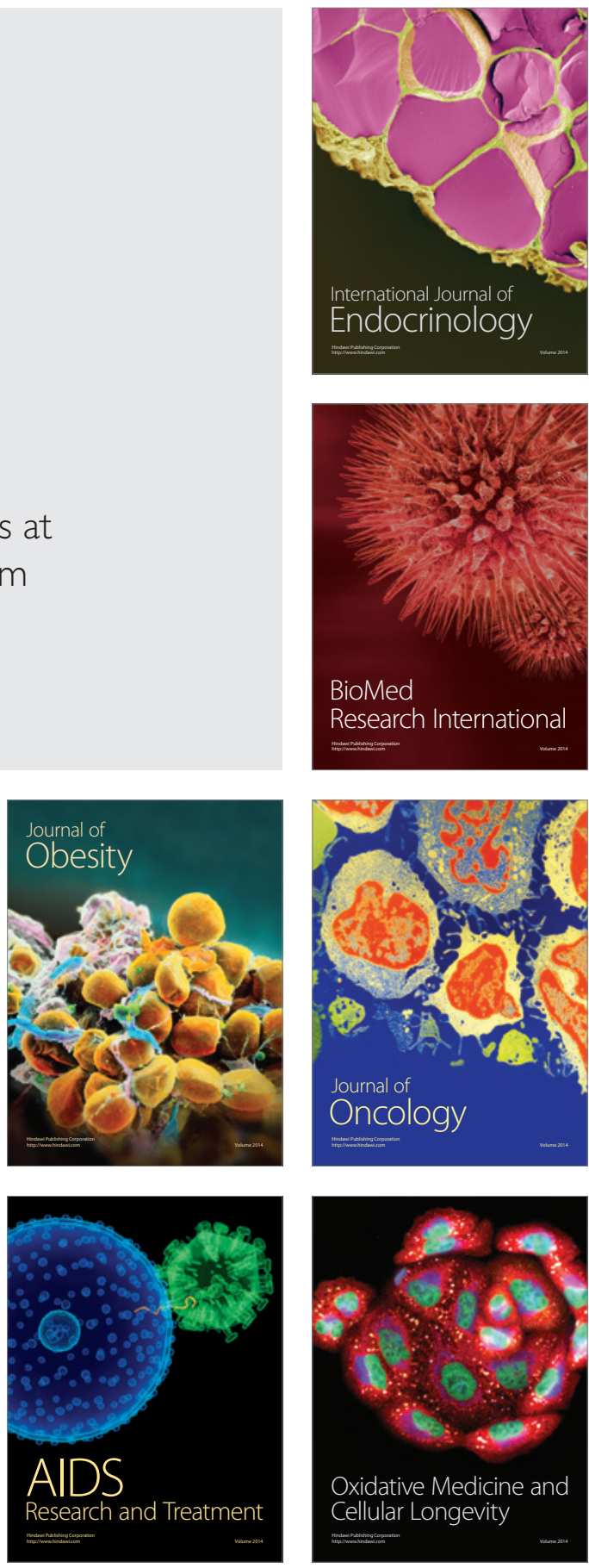